\title{
LUPUS ANTICOAGULANT HYPOPROTHROMBINEMIA SYNDROME: A CASE REPORT
}

\author{
Natalia Acedo ${ }^{1}$, Alejandro Cabrero ${ }^{1}$, Eliana Samantha Feijoó ${ }^{1}$, Cristina García ${ }^{1}$, Ana M \\ Ortiz $^{1}$, and Adrián Alegre ${ }^{1}$ \\ ${ }^{1}$ Hospital Universitario de la Princesa
}

January 13, 2022

\begin{abstract}
Lupus anticoagulant hypoprothrombinemia síndrome (LAHPS) is a rare entity. A 54-year-old woman diagnosed with systemic lupus erythematosus (SLE) present in August 2020 with cerebellar haemorrhage, coagulation factor II deficiency was found. After increasing corticosteroid dose and adjustment of immunosuppressive therapy FII levels increased. She has no presented new haemorrhagic events.
\end{abstract}

\section{LUPUS ANTICOAGULANT HYPOPROTHROMBINEMIA SYNDROME: A CASE REPORT}

Natalia Acedo ${ }^{1}$, Alejandro Alonso ${ }^{1}$, Eliana Samantha Feijoó ${ }^{1}$, Cristina García ${ }^{1}$, Ana M Ortiz ${ }^{2}$, Adrián Alegre $^{1}$

${ }^{1}$ Hematology Department, Hospital Universitario de La Princesa, Madrid, Spain

${ }^{2}$ Rheumatology Department, Hospital Universitario de La Princesa, Madrid, Spain

The authors have no conflicts of interest to declare

Written informed consent was obtained from the patient to publish this report in accordance with the journal's patient consent policy

\section{INTRODUCTION}

Lupus anticoagulant hypoprothrombinemia syndrome (LAHPS) is a rare entity consisting of lupus anticoagulant (LA) positivity associated with an acquired deficiency of coagulation factor II (FII). The origin of this deficiency seems to be associated with acquired antibodies against FII (anti-FII) ${ }^{1}$. There is evidence of the presence of non-neutralizing anti-FII antibodies in the plasma of these patients with accelerated clearance of antigen-antibody complexes in the presence of lupus anticoagulant ${ }^{2,3}$. It usually debuts in the form of hemorrhagic events, despite LA positivity ${ }^{4}$. Corticoesteroids and other immunosuppressive therapies have been used in its treatment with variable but generally favorable results ${ }^{5}$.

\section{CASE PRESENTATION}

We present the case of a 54-year-old woman diagnosed with Systemic Lupus Erythematosus (SLE) in 1996 with systemic involvement: lupus glomerulonephropathy, cutaneous, serous and joint involvement. Prior to the diagnosis of LAHPS, the patient was serologically positive por ANA, anti-DNA, anti-SSA, anti-Scl70, LA, ACAs and anticardiolipin antibodies (aCL) and was under follow-up by rheumatology in our centre. She had no personal or family history of thrombotic or haemorrhagic events and was on prophylactic antiplatelet treatment with acetylsalicylic acid (ASA) $100 \mathrm{mg}$ daily given the triple positivity for antiphospholipid antiboides. 
In August 2020, after four days of headache, the patient went to the hospital emergency department where an urgent cranial CT scan was performed showing a left cerebellar haematoma. Antiplatelet therapy was withdrawn at that time, and she progressed favourably without new haemorrhagic complications or secondary neurological sequelae. At that time, she was receiving immunosuppressive treatment with prednisone $5 \mathrm{mg}$ daily and cyclosporine 50mg every 12 hours due to her previous diagnosis of SLE. The patient had previously received multiple lines of immunosuppressive treatment as part of the treatment for her previous diagnosis of SLE and had a history of serious adverse events to immunosuppressants, including agranulocytosis secondary to treatment with azathioprine and severe infusional reaction secondary to the administration of rituximab.

The patient was referred to the thrombosis and haemostasis department for a study, which was carried out in October 2020 (Table 1).

On his first evaluation at our clinic, his platelet count was in the normal range, INR 1.44; prothrombin activity (PA) 61\%; cephalin time (PTT) 83.1 sec; cephaline mixture test (PTT) 74.9 sec; antigenic fibrinogen 408 $\mathrm{mg} / \mathrm{dl}$ and Clauss fibrinogen $360 \mathrm{mg} / \mathrm{dl}$. In view of these findings, a study of extrinsic coagulation pathway factors (coagulometric method) was performed and a deficit in FII activity (28\%) was observed. Persistent triple positivity for antiphospholipid antibodies was also observed. The study of factors of the intrinsic coagulation pathway with ellagic acid was within the normal range. The study of von Willebrands disease, filling times and platelet aggregations did not show abnormal results.

Given the suspicion of LAHPS, the dose of oral prednisona was incresed to $50 \mathrm{mg}(1 \mathrm{mg} / \mathrm{kg} /$ day $)$ daily in December 2020, after which FII activity normalised to levels of 68\% (Figure 1) in January 2021. A tapering course of corticosteroids was started two weeks after the start of treatment, reaching a dose of $10 \mathrm{mg}$ of prednisone daily in March 2021, with a parallel progressive decrease in FII activity to levels of 34\%. The patient continued to be monitored by the rheumatology department and in consensus with them, with the aim of starting a drecreasing course of corticosteroids until reaching her usual doses, the increased the daily dose of cyclosporine A and associated mycophenolate mofetil with a further increase in the levels of FII to $46 \%$ on $10 / 29 / 2021$. Given the previous adverse effects presented by the patient, it was not posible to use other immunosuppressants commonly used in other cases of LAHPS, such as azathioprine or rituximab.

On 10/29/2021 antiplatelet therapy was reintroduced with ASA 100mg daily. The patient did not present haemorrhagic or thrombotic complications.

\section{CONCLUSIONS.}

LAHPS is an uncommon pathology associated with hemorrhagic complications, more common in pediatric age and in young women, with more than half of the patients being under sixteen years of age at diagnosis ${ }^{1}$. Most cases are associated with a diagnosis of SLE or occur secondary to viral infections, the latter especially in pediatric patients, who usually present spontaneous resolution of the picture more often than in cases diagnosed in adulthood ${ }^{2}$. The management, as it has been approached in this case, consists of steroids at high doses of $\mathrm{mg} / \mathrm{kg} /$ day at the diagnosis of the disease, although there are no established parameters for the treatment of this pathology given the small number of cases described ${ }^{1}$.

The use of immunosuppressants is important for the progressive withdrawal of steroid therapy. Cyclophosphamide is one of the therapeutic options that have been used, either in combination with steroids or in monotherapy with generally favourable results ${ }^{6,7}$. Azathioprine has also been tried in this indication, always in combination with corticosteroids and with variable responses ${ }^{8,9}$. Non-specific intravenous immunoglobulins have been used as an alternative treatment in these patients, with variable responses and always in combination or after previous treatment with steroids ${ }^{10}$. Given the frequent coexistence of LAHPS and SLE in the same patient, in some cases these patients have been treated with hydroxychloroquine, with favorable results in combination with immunoglobulins ${ }^{11}$. Rituximab has been used in some patients, in combination with steroid therapy, especially in pediatric patients, with good response ${ }^{12,13}$. In our case it was not posible to use rituximab or azathioprine given the patient's history of severe adverse drug reactions to these drugs.

Combined treatment in our patient with cyclosporine A, mycophenolate mofetil and corticosteroids has so 
far allowed to maintain FII levels in the haemostatic range and to reintroduce antiplatelet therapy with ASA without documenting new haemorrhagic complications to date.

\begin{tabular}{|c|c|c|}
\hline Test & Results & Normal range \\
\hline Platelets & $235,000 / \mathrm{mm} 3$ & $150,000-450,000 / \mathrm{mm} 3$ \\
\hline I.N.R & 1.44 & $0.7-1.3$ \\
\hline Prothrombin activity & $61 \%$ & $70-130 \%$ \\
\hline Cephalin time & 83.1 seconds & 25-38 seconds \\
\hline Cephaline mixture test & 74.9 seconds & \\
\hline Fibrinogen & $408 \mathrm{mg} / \mathrm{dl}$ & $150-450 \mathrm{mg} / \mathrm{dl}$ \\
\hline Clauss fibrinogen & $360 \mathrm{mg} / \mathrm{dl}$ & $150-400 \mathrm{mg} / \mathrm{dl}$ \\
\hline Thrombin time & 11.7 seconds & $<18$ seconds \\
\hline Lupus anticoagulant & Positive & \\
\hline $\begin{array}{l}\text { PFA-100 Collagen/Epinephrine } \\
\text { Collagen/ADP }\end{array}$ & 107 seconds 76 seconds & \\
\hline Fac. VIII & $78 \%$ & $50-150 \%$ \\
\hline Fact. Von Willebrand: coR & $263 \%$ & \\
\hline Fac. Von Willebrand: Ag & $224 \%$ & \\
\hline $\begin{array}{l}\text { Anticardiolipin AC. ACA (IgG) } \\
\text { ACA (IgM) }\end{array}$ & Positive 48 GLP 30 MLP & $>20+>20+$ \\
\hline Ac Antiß2 IgG IgM & Positive 284 UI/ml 69 UI/ml & $>20+>20+$ \\
\hline Fac. IX (ellagic acid) & $75 \%$ & $50-150 \%$ \\
\hline Fac. XI (ellagic acid) & $89 \%$ & $50-150 \%$ \\
\hline Fac. XII (ellagic acid) & $67 \%$ & $50-150 \%$ \\
\hline Fac. II & $28 \%$ & $50-150 \%$ \\
\hline Fac. V & $68 \%$ & $50-150 \%$ \\
\hline Fac. VII & $95 \%$ & $50-150 \%$ \\
\hline Fac. X & $68 \%$ & $50-150 \%$ \\
\hline Prothrombin time & 15.6 seconds & $0,0-13,9$ segundos \\
\hline Fac. II inhibitor & Not detected & \\
\hline Fac. II (mixture test) & $60 \%$ & \\
\hline
\end{tabular}

Table 1. Hemorrhagic diathesis study at diagnosis (October 2020).

Authorship contribution:

1. Natalia Acedo (nataliaacedo@hotmail.com): main author, corresponding author. given final approval of the version to be published. Coordination in the drafting process. Responsible for the coagulation laboratory where the study presented in the case was performed.

2. Alejandro Alonso (aacabrero94@gmail.com): co-author, he was involved in the drafting of the article and revision of the final version.

3. Eliana Samantha Feijoó (sammyfeijoo@gmail.com): co-author, she was involved in the drafting of the article.

4. Cristina García (garciaherce.cristina@gmail.com): co-author, she was involved in the revisión of the final version.

5. Ana M Ortiz (lanult@yahoo.es): co-author, she was involved in the revisión of the final version.

6. Adrián Alegre (adrian.alegre@telefonica.net): co-author, head of haematology department. 
The author(s) declare that the research was conducted in accordance with the principles embodied in the Declaration of Helsinki and in accordance with local statutary requirements. All participants gave written informed consent to publication of this article.

Acknowledgments :

We thank the Haematology and Rheumatology Departments of the Hospital Universitario de La Princesa (Madrid, Spain) for their support in the publication of this case.

Funding:

The author(s) received no financial support for the research, authorship, and/or publication of this article.

\section{REFERENCES}

1. Mulliez SM, De Keyser F, Verbist C, Vantilborgh A, Wijns W, Beukinga I et al. Lupus anticoagulanthypoprothrombinemia syndrome: report of two cases and review of the literature. Lupus . 2015; 24:73645.

2. Bajaj SP, Rapaport SI, Fierer DS, Herbst KD, Schwartz DB. A mechanism for the hypoprothrombinemia of the acquired hypoprothrombinemia-lupus anticoagulant syndrome. Blood. 1983; 61:684-692

3. Fleck RA, Rapaport SI, Rao LV. Anti-prothrombin antibodies and the lupus anticoagulant. Blood . 1988; 72: 512-9

4. Sarker T, Roy S, Hollon W, Rajpurkar M. Lupus anticoagulant acquired hypoprothrombinemia syndrome in childhood: two distinct patterns and review of the literature. Haemophilia . 2015; 21:754-60.

5. Mazodier K, Arnaud L, Mathian A, Costedoat-Chalumeau N, Haroche J, Frances C et al. Lupus anticoagulant-hypoprothrombinemia syndrome: report of 8 cases and review of the literature. Medicine (Baltimore). 2012; 91: 251-260.

6. Taddio A, Brescia A, Lepore L, D’Rose C. Steady improvement of prothrombin levels after cyclophosphamide therapy in pediatric lupus anticoagulant syndrome (LAHPS). Clinical rheumatology . 2007; 26: 2167-2169.

7. Simel DL, St Clair EW, Adams J, Greenberg CS. Correction of hypoprothrombinemia by immunosuppressive treatment of the lupus-anticoagulant hypoprothrombinemia syndrome. American Journal of Medicine . 1987; 83: 563-6.

8. Eberhard A, Sparling C, Sudbury S, Ford P, Laxer R. Hypoprothrombinemia in childhood systemic lupus erythematosus.Seminars in Arthritis and Rheumatism . 1994; 24: 12-18

9. Erkan D, Bateman H, Lockshin MD. Lupus anticoagulanthypoprothrombinemia syndrome associated with systemic lupus erythematosus: report of two cases and review of the literature.Lupus 1999; 8:560-4

10. Pernod G, Arvieux J, Carpentier PH, Mossuz P, Bosson JL, Polack B. Succesful treatment of lupusanticoagulant hypoprothrombinea syndrome using intravenous immunoglobulins. Thrombosis Haemostasis . 1997; 78: 969-70

11. Ford A, Baca N, Buchbinder D, Mahajerin A. Lupus anticoagulant hypoprothrombinemia syndrome associated with severe thrombocytopenia in a child. Pediatric Blood $\mathcal{E}$ Cancer . 2016; 64: 1-4.

12. Cetin Gedik K, Siddique S, Aguiar CL. Rituximab use in pediatric lupus anticoagulant hypoprothrombinemia syndrome - report of three cases and review of the literature. Lupus . 2018; 27: 1190- 1197.

13. Paschal RD, Neff AT. Resolution of hypoprothrombinemia-lupus anticoagulant syndrome (HLAS) after multidrug therapy with rituximab: a case report and review of the literature. Haemophilia . 2013; 19 : $62-65$.

\section{Hosted file}

Figure 1.docx available at https://authorea.com/users/455267/articles/552613-lupusanticoagulant-hypoprothrombinemia-syndrome-a-case-report 